\title{
Profiling Occupant Behaviour in Italian Households for enhanced building simulation input: Insights into a Survey-based Investigation
}

\author{
Verena Marie Barthelmes ${ }^{1}$, Giulia Crespi ${ }^{1}$, Maria Valentina Di Nicoli ${ }^{2}$, Cristina Becchio ${ }^{1}$, \\ Valentina Fabi ${ }^{1}$, Stefano Paolo Corgnati ${ }^{1}$ \\ ${ }^{1}$ Department of Energy, Politecnico di Torino, Corso Duca degli Abruzzi 24, 10129 Torino, Italy. \\ ${ }^{2}$ Interuniversity Department of Regional and Urban Studies and Planning, Politecnico di Torino, \\ Viale Mattioli 39, 10125 Torino, Italy.
}

\begin{abstract}
The stochastic nature of the human-building interaction is an established key driver of uncertainty when it comes to the prediction of energy consumptions in buildings. To retrieve behaviour-related data on a large scale, and to avoid the setup of complex in-field monitoring strategies, survey-based investigations can be a useful tool to obtain information directly from the occupants and to profile occupancy patterns as well as energy-related daily activities in households. This paper presents a selection of outcomes of a survey-based investigation aimed at exploring (i) temperature preferences based on different household characteristics and (ii) daily energy-related activity and occupancy profiles in the context of residential buildings in Northern Italy.
\end{abstract}

\section{Introduction}

The way occupants exercise control over the indoor environment in order to meet their individual comfort criteria contributes to a large share of uncertainty when predicting building energy use and thermal comfort conditions (Masoso and Grobler, 2010; Janda, 2011). Understanding and modelling the human-building interaction, such as the regulation of heating/cooling set points, lighting levels, windows and sunscreens, or other installed HVAC systems and building envelope features, has become a pivotal task in the current research body (Yan et al., 2015). Also, occupancy patterns and occupants' energy-related daily activities evidently shape the timing and the magnitude of building energy use throughout the day. To estimate building energy use more accurately, it is crucial to understand how the users occupy the building, which daily energy-related activities they perform, how they set their comfort criteria, and consequently how they interact with the building system controls and envelope. When it is not possible to monitor the user behaviour on site and create sophisticated behavioural models, questionnaires and self-reporting are powerful tools to retrieve behavioural insights. In this context, diary-based surveys on how occupants spend their time during the day can help to shape occupancy profiles and their activities throughout the day. Indeed, as stated by Schipper et al. (1989), to gain a deeper understanding about the impact of different lifestyles on energy use, it is necessary to understand interdependencies between time use and energy consumption. At national level, a large number of countries have developed Time Use Surveys (TUS) in order to "measure how people spend their time". Initially, the aim of these surveys was to answer research questions related to social aspects, work, and economics. However, in recent years, TUS-based data has also become a source for analysing and modelling energy-related occupant behaviour, such as occupancy patterns (Richardson et al., 2008; Tanimoto et al., 2008; Aerts et al., 2014; Buttitta et al., 2017), daily energy-related activities (Wilke et al., 2013; Torriti, 2017), and related load profiles (Widén et al., 2009; Fischer et al., 2015). As regards the profiling of occupancy patterns, a lot of work has been done in the international context, while the number of Italian ad-hoc references, especially in the residential sector, is still limited. In this context, this paper is aimed at contributing to gain a deeper knowledge on occupant behaviour in the Italian residential context by providing survey-based information on time use, motivational drivers and occupancy from over 300 respondents in Northern Italy. In detail, the aim of this study is to investigate the humanbuilding interaction in North Italian households, with particular focus on heating control and temperature preferences. The survey-based investigation furthermore allows for profiling daily energy-related activities and occupancy patterns, which can be used for further implementation in building energy simulation programs in the Italian context.

\section{Methodology}

\section{Survey framework}

This section describes the survey framework used for this study aimed at gaining insights on occupant behaviour in North-Italian residential dwellings. Nowadays, with common Internet access through various types of digital devices, online surveys allow for optimizing time requirements of traditional paper surveys, as well as retrieving large-scale databases with limited costs. For this reason, the survey framework was implemented within an online open source platform, LimeSurvey (www.limesurvey.org), and could be accessed through any personal smart device (i.e. smartphones, tablets or computers). The link to the online survey was disseminated through Social Media channels (i.e. Facebook) and e-mail invitations during summer period, between 15th July 2018 to 5th August 2018. The survey was available in two languages: English and Italian. The survey structure was based on the framework developed by Barthelmes et al. (2018a; 2018b) aimed at gathering information on the human-building interaction and time 
use in 47 Danish dwellings. The survey framework was adapted to the goals of the present study and the final online version consisted of 49 main questions (varying among open, multiple choice, and continuous 5-points or 7-points Likert scale questions), divided into seven sections aiming at investigating the following aspects:

1. Individual comfort attitudes and preferences: this section was aimed at investigating individual preferences of the occupants regarding their control over the indoor environment, as well as personal comfort attitudes.

2. Individual characteristics: this section was aimed at gathering general information on the respondents (i.e. age, gender, residence, ownership of domestic animals and smoking habits), since different existing studies (Wei et al., 2014) have shown that occupants' characteristics significantly influence their perceptions of the indoor environment and their comfort attitudes.

3. Social factors: this section consisted in a set of questions investigating respondents' education, occupation, income, household/family composition, children presence, own contribution to family's energy bills, interaction with the main building control systems (i.e. thermostat, windows, lighting systems and electrical equipment).

4. Dwelling characteristics: this section was aimed at exploring building and service characteristics, such as the period of construction, year of refurbishment (if applicable), dwelling type, floor area, ownership, types of heating/cooling systems, possible presence of mechanical ventilation and renewable energy technologies, number and type of main energyintensive appliances (i.e. dishwasher, electric kitchen devices, washing machine, etc.). This information is important since building characteristics greatly influence dwellings energy performance (Ballarini et al., 2014).

5. Perceived control and psychological factors: this section was aimed at gaining insights on respondents' interactions with the building systems and envelope (i.e. thermostat regulation, operation of windows and shading devices). In particular, this section addressed users' satisfaction with the installed control options and their knowledge to operate them. Moreover, the respondents were asked to indicate their level or frequency of interaction with each of the control opportunities.

6. Motivations and habits related to window control behaviour: in this section, respondents were asked to provide information on the motivations and habits for opening/closing windows (i.e. after shower, when cooking, etc.).

7. Daily activities and time use: performed at home during the last 24 hours. This section will be further explored in "Activity and occupancy profiling".

The complete survey can be viewed in Penkala (2018). The survey link was opened 896 times during the submission period and it was compiled 611 times (476 of total survey questionnaires received were fully completed). For the analysis, only completed questionnaires were taken into account. Moreover, as the aim of the study was to gain insights into the humanbuilding interaction in the particular context of Northern Italy, respondents coming from other parts of Italy or from abroad (totally 23 respondents) were also excluded. Figure 1 depicts the percentage distribution of the respondents' age ranges. It is noticeable that the highest rate of respondents was between 13 and 29; this limited demographic spectrum is probably one of the main drawbacks of online surveys, since participants are most likely young people, as they are more familiar with use of Internet and Social Media. For this reason, it is worth noting that this study is based on responses by a limited range of population, between 13-59 years old (453 respondents). Among this range, $57 \%$ of respondents was male and $43 \%$ female.

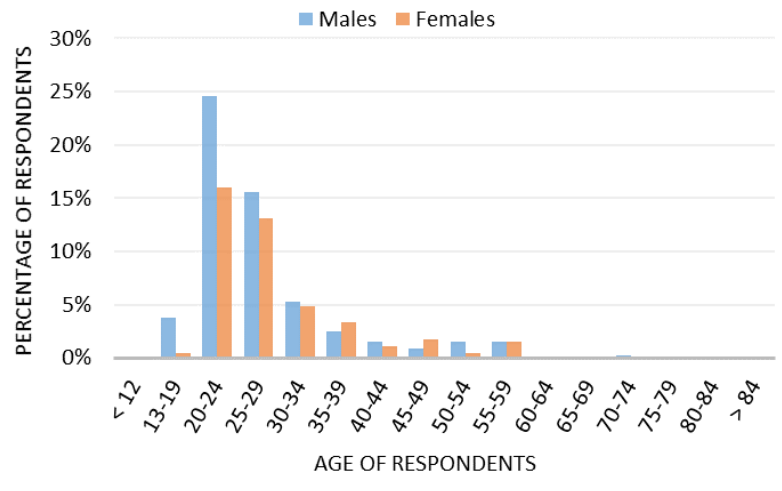

Figure 1: Percentage distribution of the respondents' age ranges.

It has to be noted that this paper focuses on section 3,4 and 7 of the survey framework since the outcomes of these sections are relevant to the investigation of temperature preferences based on different household characteristics, and the profiling of daily energy-related activities and occupancy patterns.

\section{Exploration of temperature setting preferences (i)}

Temperature settings have an important impact not only on energy consumption, but also on occupants' wellbeing and health. The basic standard of warmth in indoor environment recommended for winter by the World Health Organization (WHO, 1987) for a healthy and welldressed person is $18^{\circ} \mathrm{C}$, while temperature among $18^{\circ} \mathrm{C}$ and $21^{\circ} \mathrm{C}$ are considered comfortable. Instead, temperatures lower than $12^{\circ} \mathrm{C}$ and higher than $24^{\circ} \mathrm{C}$ during the winter season may cause health problems (cardiovascular risk) (WHO, 1987). Besides that, surely, non-adequate temperature levels affect energy consumptions and economics (energy bills). Preliminary survey results highlighted that occupants' preferences for indoor environmental temperature settings may vary significantly from person to person and may depend on many driving forces, such as social drivers (i.e. household income, children presence), physiological drivers (i.e. age of the occupant) or building characteristics (i.e. floor area, configuration of heating system). In this regard, an analysis on temperature preferences was conducted with 
respect to different household characteristics, such as floor area, income, and family composition, in order to evaluate the relation between temperature settings and different socio-economic driving forces. To do this, in the survey, respondents were asked to indicate their preferences in terms of thermostat settings for space heating.

\section{Exploration of activity and occupancy profiling (ii)}

As mentioned previously, occupants' daily activities and occupancy patterns in the building have an important impact on energy consumption. Gaining a more precise picture on energy-related activities and occupancy in specific contexts (e.g. North Italian dwellings) might allow for developing ad-hoc and context-specific input for building energy simulations. Therefore, the last part of the survey was designed to investigate daily activity profiles of the respondents, asking them to report the activities done over the last 24 hours. In particular, 10 energyrelated activities were defined (see Table 1), and respondents were asked to indicate the performed activity every 15 minutes, from 4.00 am of the day before to 4.00 am of the current day. The proposed activities were based on a clustered set of activities proposed by Barthelmes et al. (2018b). All the activities performed outside the building should be indicated in category 9, "Not at home". Based on the respondents' answers, it was possible to define average daily activity profiles. Furthermore, the definition of the category "Not at home", allowed for profiling typical occupancy patterns depicting the probability of the occupants of being at home at different hours of the day during weekdays and weekends.

Table 1: Selection of energy-related activities (Barthelmes et al., 2018b).

\begin{tabular}{|c|c|}
\hline No. & Activities \\
\hline 1 & Sleeping \\
\hline 2 & Toilette \\
\hline 3 & Eating \\
\hline 4 & Cooking/Washing dishes \\
\hline 5 & Cleaning/Washing clothes \\
\hline 6 & Practical Work \\
\hline 7 & Family care/Free time \\
\hline 8 & Relaxing/TV/IT \\
\hline 9 & Not at home \\
\hline 10 & Other \\
\hline
\end{tabular}

\section{Results}

\section{Preferences for temperature settings (i)}

In winter, the most frequent temperature range indicated by the respondents was between $19^{\circ} \mathrm{C}$ and $21^{\circ} \mathrm{C}$ (Figure $2)$, showing an average temperature among the respondents of $20.6^{\circ} \mathrm{C}$. However, the outcomes of the survey highlighted that a significant portion of occupants tend to overheat their dwellings during winter, since almost $25 \%$ of respondents usually set temperatures above $22^{\circ} \mathrm{C}$.

It was furthermore possible to link the preferences in temperature settings to a series of household and building characteristics, such as the number of occupants, the presence of children, the income, the typology of heating system and the ownership. The temperature settings distribution in function of some of these parameters is presented in Figure 3.

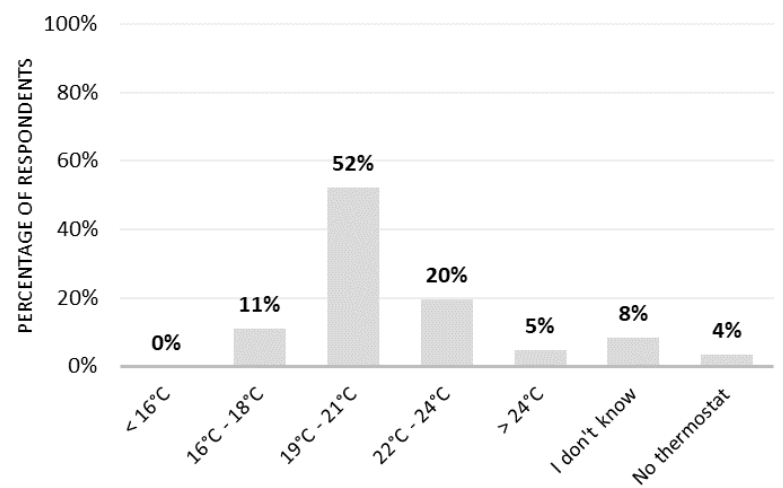

Figure 2: Thermostat set-point during winter season.

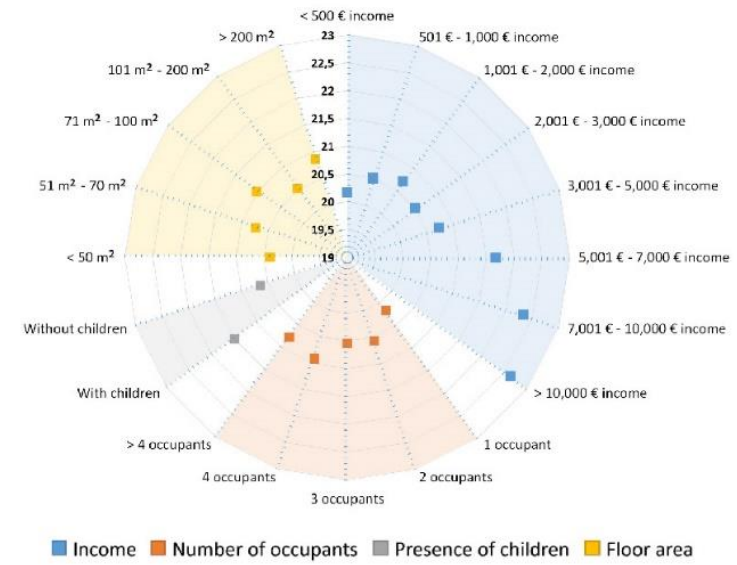

Figure 3: Thermostat set-point distribution in function of different driving forces.

In particular, the results show that the regulation of the temperature set-point usually increases with the number of household members (in orange), with a $+0.7^{\circ} \mathrm{C}$ difference between households with one member and those with four. In the case of presence of children (in grey), instead, it appeared that the average temperature set-point in dwellings with children was significantly higher (average temperature of $21.5^{\circ} \mathrm{C}$ ), compared to dwellings without children $\left(20.4^{\circ} \mathrm{C}\right)$. Buildings floor area does not strongly affect results, showing a $0.6^{\circ} \mathrm{C}$ variation among the different floor area ranges. Among economical drivers, income was selected as the most significant one; energy costs represent an important expense in Italy, where a typical family spends around $1600 € /$ year in average (1790 €/year in North-West, according to last census data in 2013 (ISTAT, 2013). Several researchers have found that households with lower income tend to use less energy for keeping warm in winter (Hunt and Gidman, 1982). This trend was confirmed in this study, as results have shown that the temperature set-point significantly increases in line with the occupants' income (in blue), varying even up to $+2.1^{\circ} \mathrm{C}$. Partially related to that, the survey permits to explore the relation between the ownership and the temperature preferences, displaying that typically occupants renting the dwellings (35\% of total respondents) tend to set higher set-points, showing a deviation between rented and owned dwellings 
of approximately $0.5^{\circ} \mathrm{C}$. Finally, in order to investigate the effect of heating system typology on temperature setpoints, it was found that centrally-heated houses appeared to have higher temperature settings (with an average difference of $0.4^{\circ} \mathrm{C}$ with respect to autonomous heating system). Moreover, 22\% of respondents who lived in dwellings with central heating system affirmed not to be aware of the temperature set-point inside their house, or not to have a thermostat to control temperature. In Figure 4 , it is possible to observe which driving forces are causing highest variations in terms of temperature settings; in particular, income appears to be the most influencing factor among those analysed, followed by the presence of children inside the building. Conversely, number of occupants and floor area generates little temperature variations.

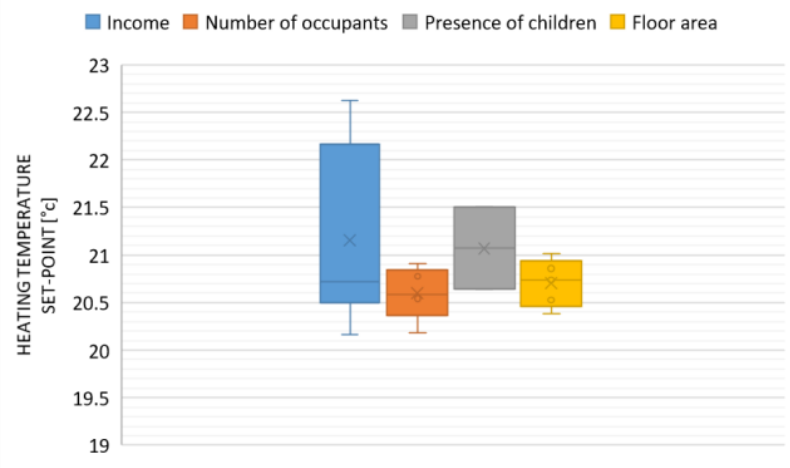

Figure 4: Thermostat set-point variation in function of different driving forces.

\section{Daily activity and occupancy profiling (ii)}

Daily activity profiles were built according to section 7 of the survey, based on respondents' reports on the activities performed over the last 24 hours, among a set of 10 predefined activities. According to the date of attendance of the survey, responses were divided to obtain answers of both weekdays and weekends, allowing shaping two profiles (Figure 5 and 6, for weekdays and weekends, respectively), to show the influence of the day of the week on energy-related activities and occupancy profiles. In relation to weekdays, Figure 5 shows that respondents are not at home for a significant portion of the day. Indeed, it is possible to note that most of the respondents are not at home during working hours in the morning ( $9 \mathrm{am}-1 \mathrm{pm})$ and in the afternoon $(2 \mathrm{pm}-6: 30 \mathrm{pm})$, and that many respondents come back for lunch (between 1 and $2 \mathrm{pm}$ ), when it is possible to foresee a peak of occupancy. Tied to this, there are two evident peaks for the "eating" activity (light grey) during lunch (around 1:30 pm) and dinner time (around 8:30 pm), the latter done concurrently with the "relaxing/TV/IT" (brown) activity, performed mostly during evening hours. As for the weekend profile (Figure 6), clearly respondents spend more time at home comparing to weekdays. The highest percentage of people who is not at home (around $40 \%$ of respondents) was noticed at 11:30 am and in the afternoon hours, from 3:30 $\mathrm{pm}$ to 7:00 pm. The duration of the "sleeping" activity (light blue) is slightly longer than during the weekdays. Moreover, during the weekends the occupants seem to spend more time on "family care/free time" activity (dark blue), showing the highest peak in the afternoon, from 3:30 pm to 5:30 pm. During weekends, occupants spend on average more time on activities as "cooking/washing dishes" (yellow), "cleaning/washing clothes" (blue) and "practical work" (green), with respect to weekdays; however, among the respondents, these activities are fairly spread out in time, not underlining any preferable time. Finally, similarly to weekdays, the average profile shows two significant peaks for the "eating" activity, for lunchtime (from 12:30 am to 2:30 pm) and dinner (7:30 pm to $9: 30 \mathrm{pm}$ ), showing nevertheless that the percentage of respondents at home during these peaks is higher compared to the weekdays average profile. From Figures 5 and 6 , it was possible to define the average time the respondents spent on the 10 energy-related activities during weekdays and weekends, reported in Figure 7.

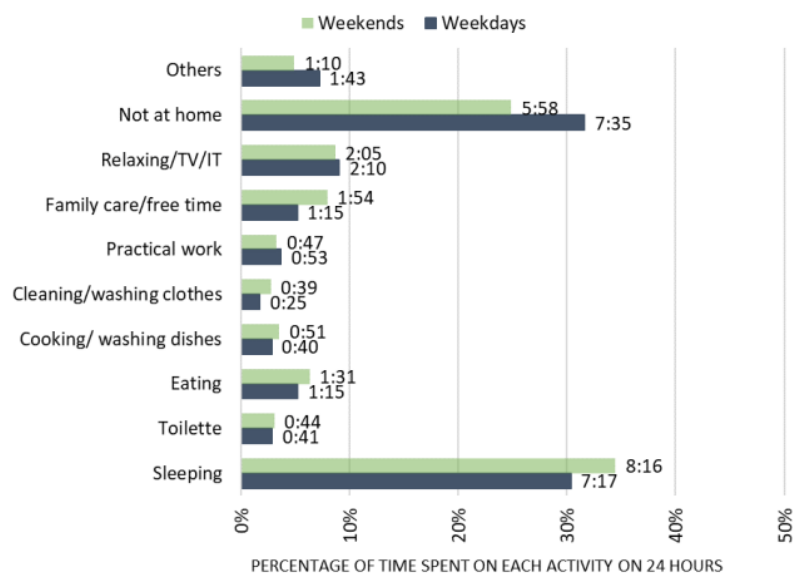

Figure 7: Daily time spent on the activities during weekends and weekdays (summer period).

Key results can be summarised as follows:

- $\quad$ longer sleeping times during weekends (8h 16m) with respect to weekdays ( $7 \mathrm{~h} 17 \mathrm{~min}$ );

- longer occupancy presence during weekends (18h 2min) with respect to weekdays (16h 25 $\min )$;

- more time spent for family care/free time during the weekends ( $1 \mathrm{~h} 55 \mathrm{~min})$ than during the weekdays (1h $15 \mathrm{~min}$ );

- $\quad$ slightly longer time spent on cooking/washing dishes and eating activities during the weekends comparing to weekdays;

- No significant difference between weekdays and weekends for other activities. 


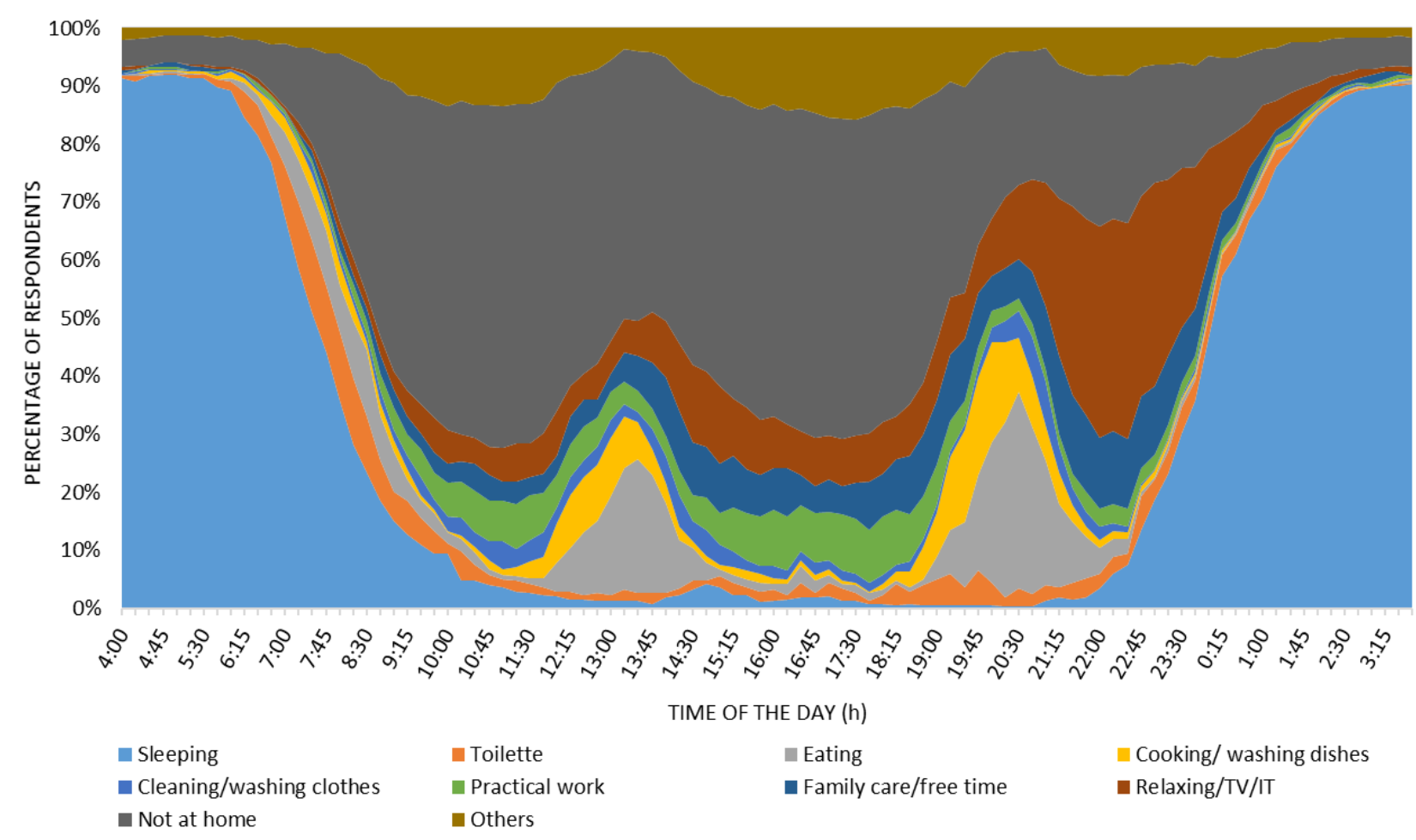

Figure 5: Daily activity profiles for weekdays (summer period).

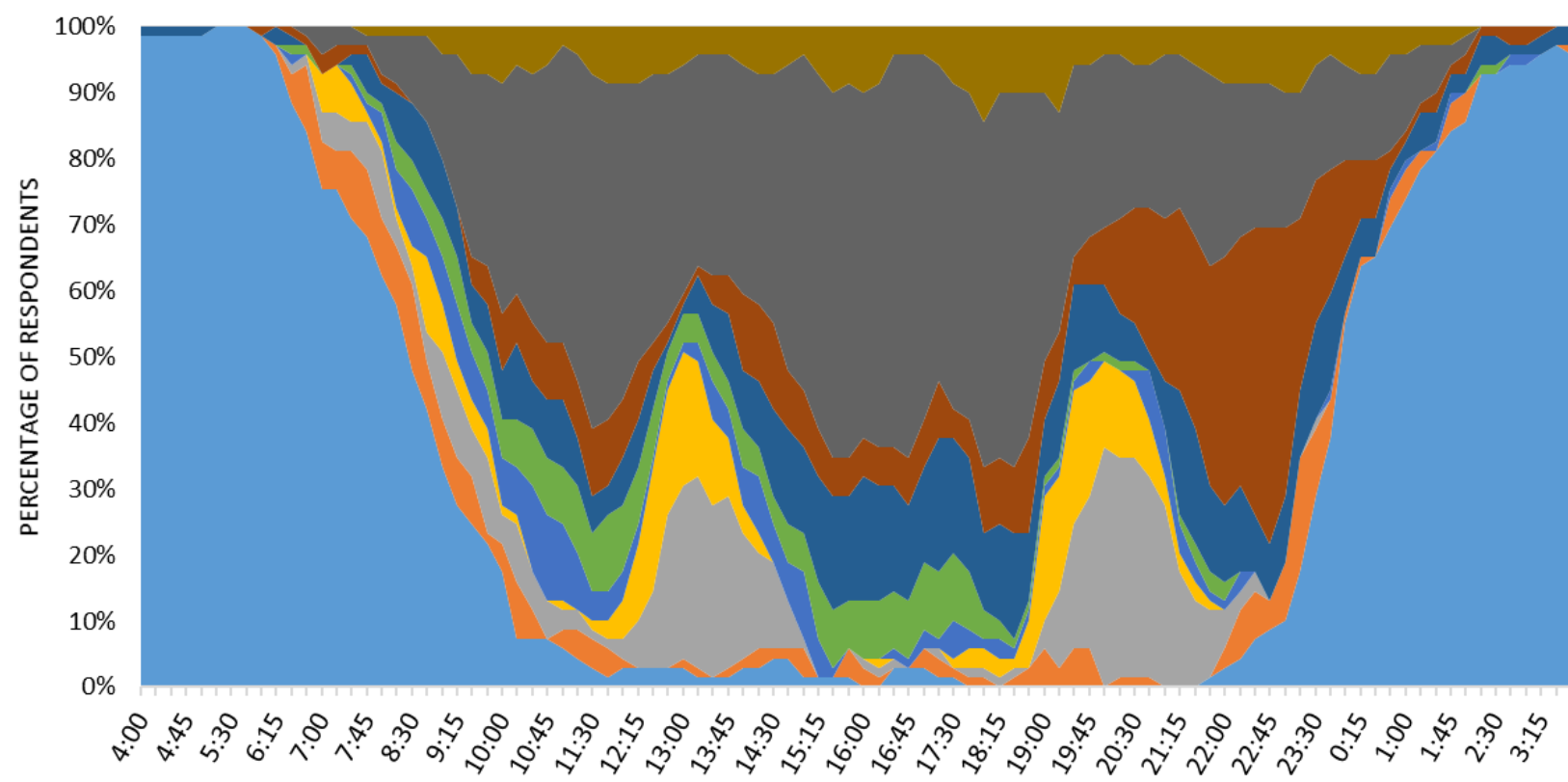

$\begin{array}{llll}\square \text { Sleeping } & \square \text { Toilette } & \text { Eating } & \square \text { Cooking/ washing dishes } \\ \square \text { Cleaning/washing clothes } & \square \text { Practical work } & \square \text { Family care/free time } & \square \text { Relaxing/TV/IT } \\ \square \text { Not at home } & \square \text { Others } & \end{array}$

Figure 6: Daily activity profiles for weekends (summer period).

From the daily activity profiles built based on respondents' preferences, it was possible to define typical occupancy profiles, presented in Figure 8, which shows the percentage of respondents at home, both for weekdays (grey) and weekends (green). 


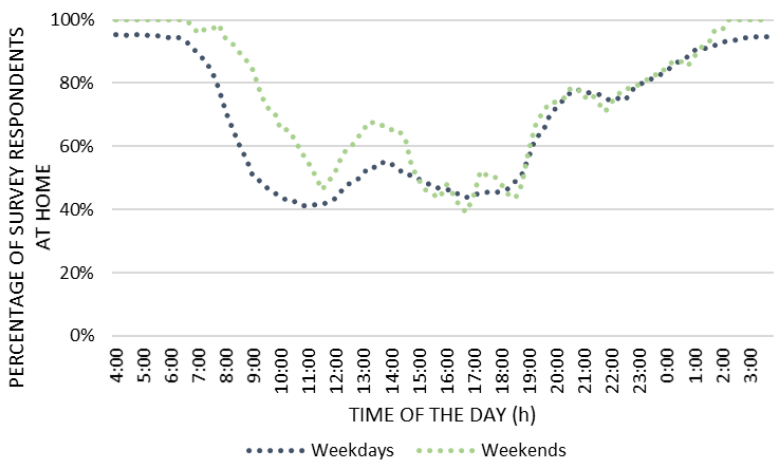

Figure 8: Occupancy profiles during weekdays and weekends.

Figure 8 highlights that the average weekday profile presents a smoother pattern with respect to the weekend profile, showing a soft peak at lunchtime and a higher one at dinnertime, when most respondents is at home. During the weekend, instead, the percentage of occupancy seems to be higher along most of the time; however, this pattern shows higher fluctuations, especially in late afternoon and evening. The two profiles almost match in late hours of the day. It is important to note that, these patterns derive from answers from respondents, mainly young people and students, partially explaining the instability of the weekend profile. Moreover, more surveys were filled during weekdays, and for this reason, the averaging procedure for obtaining the profiles provided more stable results.

\section{Discussions}

In order to test the applicability of the survey results as tailored input for energy simulation tools, the obtained profiles of energy-intensive activities were compared with typical Italian hourly mean load profiles, while occupancy schedules were verified with ones present in literature. In particular, based on the general daily activity profiles presented in Figures 5 and 6, it was possible to extrapolate daily profiles of the more-energy intensive activities ("cooking/washing dishes" and "relaxing/TV/IT"). In line with the study of Barthelmes et al. (2018b), Figure 9 depicts the comparison between the percentage of occupants performing "cooking/washing dishes" activity during weekdays and weekends and the hourly mean profile extrapolated from Capozzoli et al. (2017), which can be considered representative for Italian households (black for weekdays and grey for weekends). The hourly mean profile shows a two-peak pattern, one in the morning and the other at dinnertime. The same analysis was developed for the activity "relaxing/TV/IT", in Figure 10. Both figures show how "cooking/washing dishes" and "relaxing/TV/IT" activities are in line with the typical Italian hourly electricity profile and they appear to confirm that the typical profiles of such energyrelated activities could be related to typical Italian electricity loads of residential buildings. Indeed, the two typical peaks of the electricity pattern of a typical Italian dwelling correspond to the ones of the survey-based profiles of Figures 9 and 10.

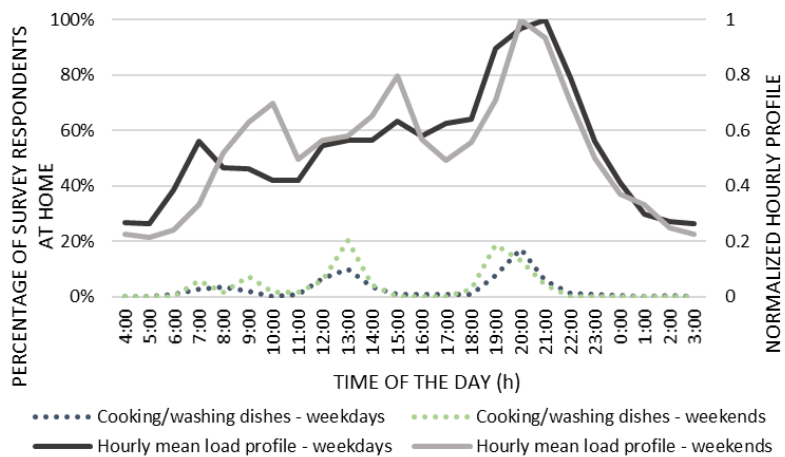

Figure 9: Comparison between "cooking/washing dishes" activity profile and hourly mean load profile (Capozzoli et al., 2017).

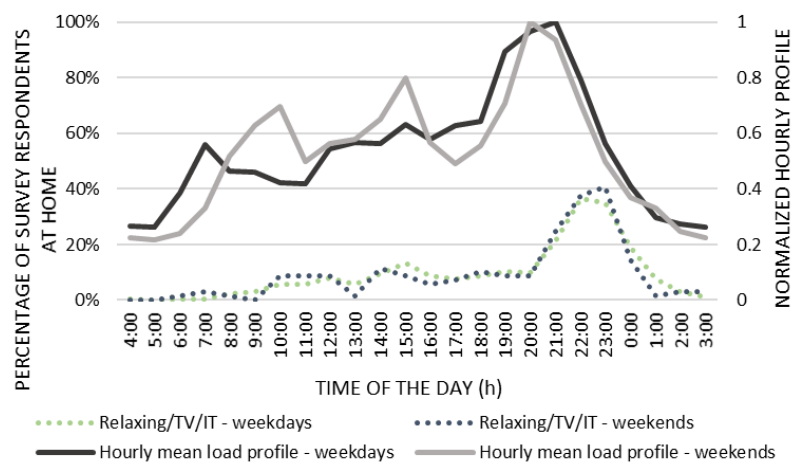

Figure 10: Comparison between "relaxing/TV/IT" activity profile and hourly mean load profile (Capozzoli et al., 2017).

As pointed out previously, Time Use Surveys can be a useful source for retrieving information on typical occupants' behaviours, which can be implemented in building energy simulation software (i.e. EnergyPlus) towards reducing the gap between simulated and real consumptions. During the simulation process, oftentimes, occupancy profiles are inserted in the form of predefined and fixed schedules. The U.S. Department of Energy (DOE) provides examples of such schedules for occupancy, lighting and electrical equipment uses, heating or cooling set-points, etc. For this reason, the occupancy profiles obtained from the survey results were compared with a DOE occupancy schedule developed for a mid-rise apartment house and valid for all days (both weekdays and weekends) (US DOE).

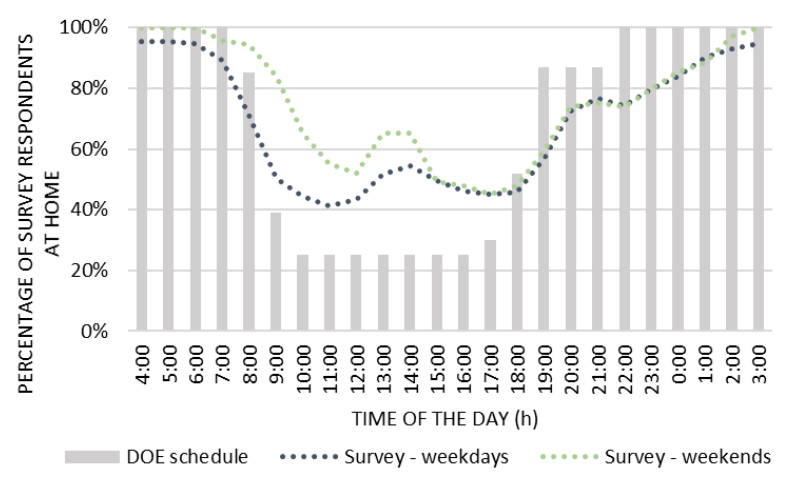

Figure 11: Comparison between DOE schedule and survey-based occupancy profile. 
Figure 11 shows that the survey-based profiles resemble the DOE ones (grey bars), even though some discrepancies can be observed, probably due to the cultural differences related to the diverse geographical context of analysis. In particular, the DOE schedule does not consider the peak during lunchtime, being flatter between 10 am and 4 pm; evening peak is clear in both profiles, as well as night behaviour. The identified differences depict the needs for more appropriate profiles for residential buildings in Italy that, to the best knowledge of authors, are still missing.

However, it has to be noted that the data underlying these survey-based profiles relied for a large extent on responses from occupants (see Figure 1) younger than the average of the Italian population, which ages between 35 and 65 (ISTAT, 2018). The study therefore surely needs to be extended to a larger sample size, which can be considered more representative for the entire (North-) Italian population. It could also be interesting to link the temperature preferences, besides the other driving forces addressed in this paper (Figures 3 and 4), for example, to age, building thermal properties and location (difference between rural and city regions), asking specific questions to respondents. Moreover, it has to be noted that the survey was filled during the summer period, and thus the obtained daily activity and occupancy profiles can be considered representative for this period of the year. These profiles might change during winter months, due to the diverse habits and behaviours occupants could have in relation to the set of energy-related activities (i.e. higher time spent at home). Future work will consist in the survey submission during winter period, in order to compare the obtained profiles. If possible, also different Italian geographical zones should be included in the analysis, to compare occupant behaviour and temperature preferences in relation to climatic zones.

Despite the limitations, the information gathered with time use investigations is fundamental for simulations. With the help of occupancy information, indeed, the planning of energy demands of buildings, as well as operational energy consumption can improve. Apart from input to energy simulation tools, survey-based information might also be integrated with Building Automation and Control Systems (BACS). Building automation could help decreasing buildings energy demand by balancing energy losses, internal gains and energy needs, with particular regard to the optimization of the balance between heating and cooling needs and providing an effective control of lighting, heating, ventilation and air conditioning systems, which is essential to guarantee a healthy, safe working and productive indoor environment. Moreover, these systems may have a significant impact also on the comfort of occupants, and they could be the answer to an energyintensive occupant behaviour, helping in increasing people awareness. Related to this, survey results on controls and habits - not presented in this paper - showed that a significant portion of people is not aware on the influence they can have on energy consumptions. $60 \%$ of respondents stated that they open the window even if the heating system is on, and, among people with mechanical ventilation systems installed, approximately $72 \%$ open windows while ventilation is active. For this reason, and mainly with the introduction of the smart building concept (European Commission, 2018), recent research is focused on limiting occupancy effect on energy consumptions. A possible solution in this sense could be the use of Time Use Surveys for linking occupancy information with BACS. Building automation systems can be managed with the introduction of predetermined schedules, to take into account occupancy patterns in the systems control logics. For instance, only when the time range corresponds with the predefined schedules, an action is implemented by the building systems (i.e. switch on the light, turn on the heating system, etc.). With the use of the time use based investigation, as presented in the paper, it is possible to obtain occupancy profiles (Figure 8) or sleeping schedules (from Figures 5 and 6) for both weekdays and weekends. In this regard, thanks to the survey-based schedules, it could be possible to develop control logics, not just focused on the energy savings, but also on occupants' preferences and habits. In particular, as depicted in Figure 12, survey results could be used as input for optimization strategies of building automation systems, in order to reduce the number of sensors to be installed within buildings and use adaptive and userdefined schedules at once.

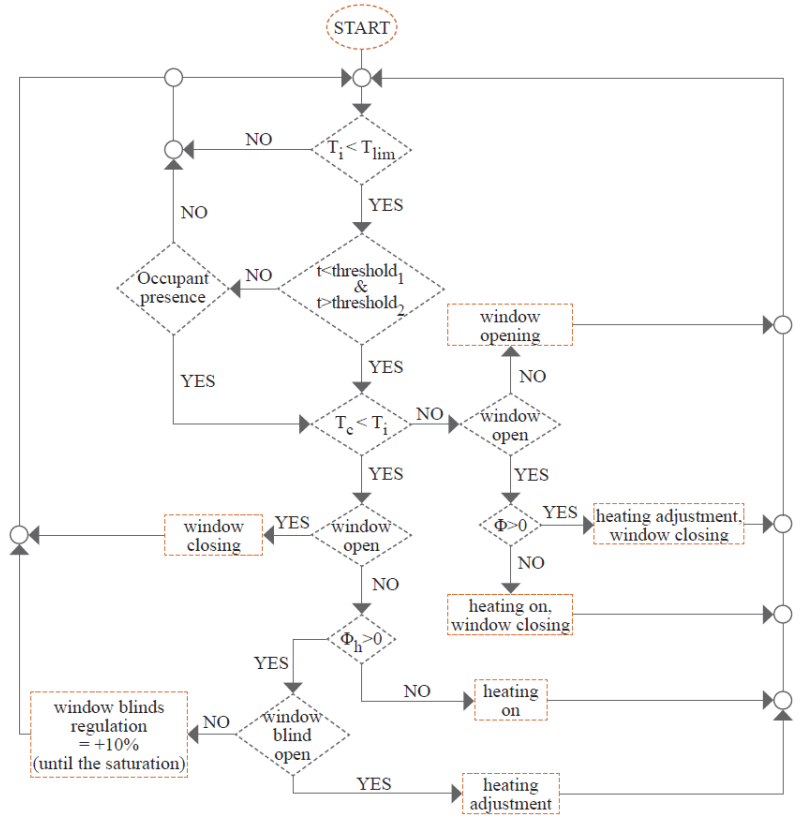

Figure 12: Example of highly automated control logic for indoor temperature, in winter season.

Future work is needed to further investigate the integration of survey-based schedules and building automation control logics, in appropriate modelling framework, in order to validate the positive effect that the knowledge of occupancy profiles can have on reducing energy consumptions and increasing occupants' satisfaction within the building. 


\section{Conclusion}

For investigating the human-building interaction in the Italian residential context, a questionnaire survey was conducted in north-Italian dwellings at the beginning of summer 2018. The survey framework included questions about individual preferences for indoor environmental conditions, individual characteristics of the occupants (i.e. age, gender), social factors (i.e. education, job category, and household income), dwelling characteristics, and occupant interaction with the building systems and with windows. Furthermore, in order to shape energy-related activities, the respondents were asked to report their activities performed at home during the last full day, choosing for every 15-minutes intervals among the proposed activities. This study provided insights on heating control and temperature preferences of the residents. Daily energy-related daily activities and occupancy patterns were profiled as preliminary input for building simulation programs, as well as optimization strategies for building automation control.

\section{Acknowledgement}

This paper is based on the master thesis developed by Klaudia Penkala (Penkala, 2018).

\section{References}

Aerts, D., Minnen, J., Glorieux, I., Wouters, I., Descamps, F. (2014). A method for the identification and modelling of realistic domestic occupancy sequences for building energy demand simulations and peer comparison. Building and Environment 75, 67-78.

Ballarini, I., Corgnati, S.P., Corrado, V. (2014). Use of reference buildings to assess the energy savings potentials of the residential building stock: the experience of TABULA project. Energy Policy 68, 273-284.

Barthelmes, V.M., Andersen, R.K., Heo, Y., Knudsen, H., Fabi, V., Corgnati, S.P. (2018a). Introducing thermal comfort attitudes, psychological, social and contextual drivers in occupant behaviour modelling with Bayesian Networks. Proceedings of 10th Windsor Conference: Rethinking Comfort. Windsor (UK), 1215 April 2018.

Barthelmes, V.M., Li, R., Andersen, R.K., Bahnfleth, W., Corgnati, S.P., Rode, C. (2018b). Profiling occupant behaviour in Danish dwellings using time use survey data. Energy \& Buildings 177, 329-340.

Buttitta, G., Turner, W., Finn, D. (2017). Clustering of Household Occupancy Profiles for Archetype Building Models. Energy Procedia 111, 161-170.

Capozzoli, A., Corgnati, S.P., Di Nicoli, M.V., Fabi, V., Piscitelli, M.S., Spigliantini, G. (2017), Attività di monitoraggio energetico e ambientale, diagnostica ed Energy Engagement degli utenti degli use case. Report Ricerca di Sistema Elettrico RdS/PAR2016/008.

European Commission. (2018). Energy Performance of Buildings Directive, $2^{\text {nd }}$ recast, DIRECTIVE (EU) 2018/844. 30 May 2018.
Fischer, D., Härtl, A., Wille-Haussmann, B. (2015). Model for electric load profiles with high time resolution for German households. Energy \& Buildings 92, 170-179.

Hunt, D.R.G. and Gidman, M.I. (1982). A national field survey of house temperatures. Buildings and Environment 17, 107-124.

Istituto Nazionale di Statistica, ISTAT (2013).

Istituto Nazionale di Statistica, ISTAT (2018).

Janda, K. (2011). Buildings don’t use energy - People do! Planet Earth, (WINTER), 12-13.

Masoso, O.T. and Grobler, L.J. (2010). The dark side of occupants' behaviour on building energy use. Energy \& Buildings 42, 173-177.

Penkala, K. (2018). Occupant behaviour vs energy consumption in a residential building. Master Degree Thesis. Politecnico di Torino.

Richardson, L., Thomson, M., Infield, D. (2008). A highresolution domestic building occupancy model for energy demand simulations. Energy \& Buildings 40, 1560-1566.

Shipper, L., Bartlett, S., Hawk, D., Vine, E. (1989). Linking Life-Styles And Energy Use: A Matter Of Time?. Annual Review of Energy and the Environment 14, 273-320.

Tanimoto, J., Hagishima, A., Sagara, H. (2008). Validation of probabilistic methodology for generating actual inhabitants' behavior schedules for accurate prediction of maximum energy requirements, Energy \& Buildings 40, 316-322.

Torriti, J. (2017). Understanding the timing of energy demand through time use data: Time of the day dependence of social practices. Energy Research \& Social Science 25, 37-47.

US Department of Energy (DOE). Residential Buildings Integration _ Department of Energy.

Wei, S., Jones, R., De Wilde, P. (2014). Driving factors for occupant-controlled space heating in residential buildings. Energy \& Buildings 70, 36-44.

Widén, J., Nilsson, A.M., Wäckelgård, E. (2009). A combined Markov-chain and bottom-up approach to modelling of domestic lighting demand. Energy \& Buildings 41, 1001-1012.

Wilke, U., Haldi, F., Scartezzini, J., Robinson, D. (2013). A bottom-up stochastic model to predict building occupants' time-dependent activities. Building and Environment 60, 254-264.

World Health Organisation, WHO (1987). Health Impact of Low Indoor Temperatures.

Yan, D., O’Brien, W., Hong, T., Feng, X., Gunay, H.B., Tahmasebi, F., Mahdavi, A. (2015). Occupant behavior modeling for building performance simulation: Current state and future challenges. Energy \& Buildings 107, 264-27. 